\title{
EL EDITOR COMO AUTOR: PRÁCTICAS ECDÓTICAS EN TEXTOS EPISTOLARES
}

\author{
EDITOR AS AUTHOR: ECDOTIC PRACTICES \\ IN EPISTOLARY TEXTS \\ Andrés JUÁREZ LÓPEZ \\ Universidad Nacional de Educación a Distancia \\ aj171967@gmail.com
}

\begin{abstract}
Resumen: La constante publicación de textos epistolares en España contrasta con la ausencia de una reflexión sistemática sobre sus criterios de edición. Además, las especiales características de la carta privada propician, de modo significativo, la apropiación de decisiones autoriales por parte del editor. En el presente artículo se aborda la figura del editor como autor en los procesos ecdóticos de selección, disposición y transcripción de los materiales epistolares, a través del examen de setenta y cinco ediciones de correspondencia. Ello permite dibujar la orientación y mecanismos de tales apropiaciones y su tendencia a la alteración ficcional de textos documentales y autobiográficos.
\end{abstract}

Palabras clave: Ecdótica. Cartas. Epistolarios. Editor. Autor.

\begin{abstract}
The constant publishing of epistolary texts in Spain makes a contrast with the lack of a systematic reflexion about its editing criteria. The private letter's special features also lead to a significant appropriation of authorial decisions by the editor. On this article, we adress the figure of the editor as author in the selection, arrangement and transcription processes for epistolary materials through the exam of sixty five correspondence editions. This makes it possible to draw the orientation and mechanisms of such appropriations and their trend to fictional alterations on documentary and autobiographical texts.
\end{abstract}


Key Words: Ecdotic. Letters. Collected letters. Editor. Author.

\section{EL EDITOR COMO AUTOR. LA PROBLEMÁTICA EDICIÓN DE TEXTOS EPISTOLARES}

La publicación de epistolarios de escritores no ha cesado de crecer a lo largo de los últimos años en el panorama de la edición española. Desde los primeros balances y planteamientos de investigación filológica (Díez de Revenga, coord., 1998; Morelli, ed., 2001; Neira, 2002), hasta las más recientes compilaciones de estudios dedicados a las correspondencias y los epistolarios (Dolfi y Bernal, eds., 2014; Teruel, ed., 2018) el incremento de ediciones no ha dejado de mantenerse de forma sostenida. A lo largo del último cuarto de siglo podemos contar por decenas las ediciones de cartas, fundamentalmente de autores contemporáneos, con una acusada preferencia por los de la denominada Edad de Plata.

Los propios editores y estudiosos señalan varios focos de interés en estos textos. Al autobiográfico (Pagés-Rangel, 1997a y 1997b), se añade su aportación como documentos de primer orden para la historiografía literaria y cultural (Torras, 2001; Fernández y Ortega, eds., 2008; Martos y Neira, eds., 2018). También han sido valorados como instrumento para la recuperación de la memoria colectiva de un determinado momento histórico (Díaz de Castro, 1998). A estos intereses se suma el del propio valor estético de la escritura epistolar, el de su constante tensión hacia la literariedad, aspecto abordado en el plano teórico por un consumado epistológrafo como Pedro Salinas en su "Defensa de la carta misiva y de la correspondencia epistolar", ensayo incluido en El Defensor (1967: 42-43). Precisamente, esta tendencia a lo estético y literario ha sido el criterio para ediciones como las Cartas de viaje de Pedro Salinas (1996), al cuidado de Enric Bou.

Sin embargo, esta significativa abundancia de ediciones no ha venido acompañada de una reflexión integral y rigurosa sobre la tarea ecdótica correspondiente, toda vez que los textos epistolares, por sus especiales características, la requieren con tanta o incluso mayor exigencia que otro tipo de textos literarios. En este sentido, salvo contadas aportaciones (Neira, 2000, 2002, 2003 y 2018; Stanley, 2004; Lluch-Prats, 2011; Thion, 2017), y proyectos colectivos como Epistol@ (González García, 2014) 
solo disponemos de reflexiones parciales o indirectamente relacionadas con la tarea de la edición, a las que debemos sumar las desiguales prácticas ecdóticas reflejadas en las diferentes ediciones. Salvando las excepciones mencionadas, estas ediciones conforman, en efecto, el núcleo del corpus teórico del que disponemos acerca de la edición de documentos epistolares, valioso sin duda en algunos casos, pero ceñido a las peculiaridades de cada colección epistolar editada y limitado a las "notas a la edición”, cuando las hay, de las propias publicaciones, con unos breves párrafos dedicados a las decisiones y estrategias ecdóticas.

Como ha señalado Neira refiriéndose a la edición de epistolarios de autores del 27 anteriores a la puesta en marcha del mencionado proyecto Epistol@:

Hasta entonces, sin embargo, la edición de epistolarios del Veintisiete se había producido en los últimos lustros del siglo XX de una manera asistemática, sin una reflexión teórica previa y con bastante improvisación metodológica, por lo que su resultado es una variadísima tipología de ediciones (2018: 118).

Pese a los indiscutibles avances, durante los cuatro primeros lustros del siglo XXI la publicación de epistolarios ha continuado creciendo y siguen siendo minoría, entre el conjunto de las que se van publicando, las ediciones con criterios homogéneos y adoptados tras una reflexión filológica detenida.

Con el objetivo de subsanar parcialmente esta escasa atención teórica, en las siguientes páginas abordaremos algunos aspectos de una posible ecdótica epistolar. Tomaremos como presupuesto de investigación la figura el editor como autor, que consideramos central tanto en la práctica de las ediciones como en el enfoque teórico de la edición epistolar. Para ello atenderemos a las características del género como definitorias y condicionantes de las decisiones ecdóticas que tales textos requieren. Además, prestaremos atención especial a una de estas notas definitorias, la no preparación de los textos para su publicación por parte de los autores. Este último aspecto, a nuestro juicio, resulta determinante pues implica la activación de la figura del editor como autor y su proyección en todas y cada una de las fases de la edición epistolar. Como indican Garriga y Teruel (2018: 12): 
[...] en el momento en que el artefacto epistolar supera las parcelas delimitadas por el emisor y el receptor y se lanza, ya sea por vía manuscrita o por vía impresa, con el consentimiento del autor o sin él, al mercado editorial, la figura del autor de cartas se desdibuja y editores e impresores, de un lado, y los propios lectores, de otro, se adueñan del timón de transmisión epistolar. Pese a la tendencia general de entender los epistolarios editados póstumamente como un todo orgánico, no debemos olvidar que los epistolarios constituyen casi siempre corpus textuales no fijados, en continuo movimiento, que los editores, que seleccionan, descartan, ordenan y transcriben el material epistolar, se erigen inevitablemente como coautores del texto.

Nos proponemos, por tanto, identificar y examinar, desde una perspectiva ecdótica, las formas de apropiación de estas decisiones autoriales por parte del editor, rastreándolas en las diferentes fases del proceso de edición.

Utilizaremos para ello algún ejemplo de ediciones del siglo XIX, pues la perspectiva temporal otorga gran transparencia a las decisiones adoptadas, pero centraremos nuestra atención, mayoritariamente, en la producción editorial de los últimos años. A tal fin, hemos consultado cinco ediciones realizadas en el siglo XVIII, diez en el XIX, veinticinco en el XX y treinta y cinco en el siglo XXI. De ellas, naturalmente, solo mencionamos los casos pertinentes para nuestro examen de la figura del editor como autor.

\section{EL MOSAICO EPISTOLAR: DEL ARCHIVO DOCUMENTAL A LA SELECCIÓN DE LA MATERIA EPISTOLAR}

Demetrio el Cínico (1996), en Sobre el estilo, tratado cuya fecha de composición desconocemos, pero datable entre el siglo II a.C. y el I d.C., nos deja las primeras reflexiones extensas de las que tenemos constancia dedicadas al género epistolar. Su autor señala ya en fecha tan lejana algunos rasgos del género sobre los que volveremos: su carácter dialógico, la importancia de la autorrepresentación del emisor (Demetrio, 1996: 9697) y las múltiples posibilidades de estructura y contenidos (Demetrio, 1996: 98). Estas notas implican una especial configuración del género, con 
un mayor grado de apertura frente al resto de los géneros considerados en la poética clásica (épica, drama, lírica). Además, su carácter no mimético (no ficcional, diríamos hoy) lo sitúa frente al resto de géneros en un espacio propio.

Entre los estudiosos contemporáneos, contamos con una amplia catalogación de las notas del género, todas ellas enmarcadas en ese mismo espacio de multiplicidad de posibilidades: género oral y a la vez escrito (Guillén, 2008: 112; Gadamer, 1977: 446-447), histórico y literario (Pulido, 2001; Caballé, 2006: 199-201; Bou, 2006: 252), capaz de mimetizarse en la autobiografía, el ensayo, la narrativa o la lírica, lo que compromete y tensa su carácter no ficcional, aspecto este último que señaló Claudio Guillén al hablar de "la ilusión de la no ficcionalidad" (1998: 177).

En este contexto, Altman (1982) nos ofrece un análisis de las notas del género epistolar de enorme utilidad. Y el hecho de que estudie obras epistolares de ficción - novela epistolar de los siglos XVIII y XIX, fundamentalmente - con unas conclusiones aplicables en su práctica totalidad a las características de la carta real, privada o no ficcional, reafirma el carácter fronterizo del género, su doble dimensión de documento histórico y literario.

En este sentido, una de las categorías de mayor rendimiento para estudiar los mecanismos de edición de textos epistolares es la que Altman denomina como el "mosaico epistolar" (1982: 167-185). La carta, nos dice a propósito de la novela epistolar, tiene un estatus independiente y dependiente simultáneamente. Entra en un todo organizado sin perder su unidad propia y sus límites racionales, su propio tono. El mosaico epistolar implica tramas múltiples, cortes de la línea temporal, multiplicidad de corresponsales y también lagunas. Los huecos entre unidades, señala Altman, tienden a ser cerrados por la narrativa epistolar. Con todo, los espacios vacíos resultan más nítidos que en la novela no epistolar, donde son suavizados por el narrador:

But whatever the editorial style, what always distinguishes epistolary fictions from nonfictional letters is the space of structured interplay they leave between letters. This space is the trace of the "editor", of that very editor who typically claims elsewhere to have played a minimal role. The epistolary novelist who effaces himself from the tittle page thus reappears in the text; but his most compelling voice is not the one that speaks to us in editorial prefaces and footnotes. The creator of epistolary novel who 
disclaims authorship reclaims it elsewhere-in the very joint work that structures the epistolary mosaic as art (Altman, 1982: 183).

Consideramos que esta caracterización del autor como editor que Altman describe en el ámbito de la novela epistolar puede trasvasarse a la figura del editor como autor en la edición de cartas reales. Y que las características del género condicionan y propician tales comportamientos, orientados en ambos casos a una formalización enmarcada en la categoría del mosaico epistolar. Que tal mosaico se realice "as art", como un arte, nos lleva a reflexiones relacionadas con las múltiples posibilidades ecdóticas.

En efecto, si nos trasladamos del ámbito ficcional al real o no ficcional, los editores de cartas se enfrentan a un depósito documental que puede presentarse de variadas formas. Las dimensiones a veces inabarcables de tal depósito, su estado fragmentario e incompleto o su dispersión, obligan al editor a una primera decisión: la selección voluntaria o forzosa del material al que dar forma. La multiplicidad de opciones del editor, aparentemente naturales una vez procesadas a través de la edición y publicación, son la primera apropiación autorial efectuada. Pues el primer paso de una edición epistolar consistirá en decidir qué cartas - porque frecuentemente se trata de una selección- entrarán a conformar la edición.

Esta constatación nos sirve para acercarnos a una categoría, la de archivo, que conviene examinar. De un autor tenemos, pensando en la totalidad de las cartas salidas de su mano, un hipotético archivo del que nunca podremos decir que está completo, pero que constituye la obra completa epistolar de la que el editor selecciona el material que se dispone a editar. A ello habrá que sumar las cartas recibidas en respuesta a las enviadas. Ambos grupos de documentos se encontrarán, salvo excepciones, en espacios físicos distintos, en dos archivos documentales distintos, el del propio autor, en el caso de las cartas recibidas, y disperso en los archivos de cada destinatario, en el caso de las enviadas.

Y aquí resulta pertinente aplicar a la práctica ecdótica la categoría de mosaico que Altman señalaba a propósito de la autonomía de la carta y de su pertenencia a un conjunto, de su dependencia e independencia simultánea. La carta, unidad aislada, es una de las teselas de un mosaico que adoptará una forma y un sentido precisos en la medida en que seleccionemos y unamos unas piezas determinadas en lugar de otras. Y esto, casi siempre, es iniciativa del editor. 
En cualquier caso, la naturaleza del archivo al que el editor se enfrenta condiciona los ulteriores procesos de edición. Así, podemos encontrarnos ante un archivo epistolar de dimensiones difícilmente abarcables para una edición puntual. Pensemos, por ejemplo, en el archivo epistolar de Jorge Guillén, depositado en la Biblioteca Nacional de España ${ }^{1}$. Del mismo contamos con un catálogo descriptivo de más de 500 páginas, con cerca de 3.400 corresponsales y decenas de miles de unidades epistolares, entre las enviadas y las recibidas por el poeta, en un arco temporal que abarca desde las primeras de las remitidas a su padre, en 1900, hasta las de 1984, año de su fallecimiento. A ello hay que sumar los archivos de Wellesley College, de Harvard University Library y de la Fundación Jorge Guillén de Valladolid, que complementan al de la Biblioteca Nacional de España. Como es fácil suponer, el inmenso yacimiento de datos, testimonios, reflexiones y voces reunidos en tal archivo obliga a una forzosa selección, tanto como a asumir que el mosaico completo, abarcador de la entera correspondencia conservada, implicaría un proyecto imposible de afrontar por un único editor y aun en el caso de un equipo de investigadores requeriría un plazo de ejecución considerable.

Ante tal imposibilidad es necesario tomar conciencia de que en una edición al uso contaremos con un mosaico parcial y a la vez incompleto en su dimensión biográfica, histórica o literaria y de que el corpus editado, en este sentido selectivo, es decisión y obra del editor.

Y el de Jorge Guillén no es caso aislado. Por citar solo dos casos similares, los archivos de Carmen Conde o Manuel de Falla ofrecen un balance equivalente. Pese a la vitalidad de la edición de cartas durante los últimos años y a la vista de las cifras que nos ofrece un somero examen cuantitativo, el trabajo de edición pendiente resulta de dimensiones difícilmente abarcables.

Por otra parte, debemos considerar también los archivos privados o semiprivados, sin catalogar y a veces en situación de enorme precariedad documental, dependientes de la voluntad de familiares y depositarios para facilitar el acceso a los investigadores y una posible edición y publicación. Es el caso de decenas de escritores y pensadores de indudable significación que permanecen en la oscuridad y en el silencio de sus archivos.

${ }^{1}$ http://www2.bne.es/AP_publico/irVisualizarFondo. do? idFondo $=29 \&$ volverBusqueda $=$ irBuscarFondos.do [11/11/2019]. 
Insistimos en que ante tal variedad de situaciones y posibilidades el editor de cartas se enfrenta a una primera decisión que habitualmente, en el caso de otros géneros editados en vida del autor, cae en el perímetro de la voluntad de este. De entre la gigantesca cantidad de documentos depositados en los archivos públicos o privados, ordenados o dispersos, catalogados o simplemente reunidos de la mejor forma posible por sus depositarios, el editor elige, decide y selecciona, según sus intereses y objetivos de investigación, una parcela de tales archivos. De tal modo que, para el conjunto documental completo, podemos hablar de una autoría primaria, la evidente e indiscutida del escritor del texto, pero la selección del editor imprime una autoría complementaria que se superpone a aquella.

Tampoco debemos olvidar los condicionantes de carácter comercial, legal o material de la propia edición. Estos influyen en el número de páginas del volumen, como lo hacen la posibilidad de contar con recursos y respaldo institucional para una edición en gran formato o la obtención de los permisos legales por parte de herederos o depositarios, necesarios para la publicación.

Examinemos ahora brevemente el rango cualitativo de las selecciones realizadas, en un espacio que limita ya con otra operación ecdótica, la disposición del material. Las decisiones más habituales han sido descritas por Neira (2000, y, especialmente, 2002: 381-413) al abordar la tipología de ediciones de los epistolarios del 27. Observamos una preferencia mayoritaria por la edición de cartas cruzadas entre dos corresponsales, bien en una única dirección (quince ediciones de las consultadas) o en la doble dirección de ida y vuelta (veinticinco). También encontramos colecciones compuestas por cartas de un emisor con múltiples destinatarios (nueve ediciones), en las que hallamos a los autores más asentados en el canon, como Leandro Fernández de Moratín (1973) en el ámbito del XVIII o, ya en el siglo XX, Federico García Lorca (1997) o Pedro Salinas (1996), entre otros; más laboriosas ecdóticamente, pues se encontrarán dispersas en los archivos de los destinatarios, estas son ediciones centradas en el foco del emisor. Las colecciones de múltiples autores que remiten cartas a un único destinatario las constituyen los documentos que hallaremos reunidos en el archivo del destinatario (es el caso, por ejemplo, de las Cartas a Rosa Chacel, editadas por Ana Rodríguez Fischer en 1992). Hallamos también, aunque con menor frecuencia, cartas cruzadas entre varios destinatarios y emisores, en direcciones múltiples (Diego, 2001 y 2003; Diego, Guillén y 
Salinas, 1996; Guillén y Salinas, 2016).

En algunos casos, la selección es solo aparente y viene determinada por la naturaleza del archivo, pues nos encontraremos con una laguna de este último, más que con una decisión del editor. Así, el carácter unidireccional puede venir condicionado por la pérdida de material de uno de los corresponsales. Podemos también hallar vacíos temporales debidos a conflictos bélicos (por ejemplo, los años de la guerra civil española, que suponen un hiato en la mayoría de las correspondencias de la primera mitad del siglo XX), exilios o destrucción parcial de los archivos, como es el caso del incendio del pazo de Meirás en el año 1978, todavía por esclarecer en sus precisos detalles, que supuso, aparentemente, la destrucción de buena parte del legado de doña Emilia Pardo Bazán, un depósito documental de valor incalculable.

Los Epistolarios completos son, en este conjunto, minoritarios, aunque no faltan ejemplos como los de Federico García Lorca (1997), a cargo de Andrew A. Anderson y Christopher Maurer o Manuel Altolaguirre (2005) en edición de James Valender, entre otros.

Tras este repaso, vemos que la selección es cuantitativamente parcial, aunque con el sentido y la coherencia otorgados cualitativamente por el editor a través de una determinada vinculación de corresponsales, de asuntos o de marco temporal. Si enfocamos nuestra atención en el material elegido, atisbamos aquí de nuevo el mosaico que Altman, hablando de la novela epistolar, calificaba "as art". El editor tiende a crear una selección a la que otorga una orientación determinada, prefigurada en el archivo pero solo formalizada en el trabajo de edición.

En la mayoría de las ocasiones, la decisión adoptada deja una parcela enorme de la producción epistolar en la sombra no solo de lo inédito, sino de lo ignorado. Por ello sería conveniente que el editor, al decidirse por una selección determinada, apuntase una descripción lo más detallada posible del archivo. Se trataría de indicar al menos sus corresponsales, el volumen del corpus documental, su marco temporal y sus características materiales.

Porque una selección, aunque dotada de sentido y coherencia, ofrecerá una imagen parcial e incompleta, filtrada por la decisión del editor. Reencontramos en este proceso la ya mencionada tendencia a la literariedad de la escritura epistolar y su constante impulso a la ficcionalización, señalados por Pedro Salinas (1967) y Claudio Guillén (1998). Esta tendencia, a nuestro juicio, también se hace presente en la 
labor ecdótica. Pues el editor potencia elementos de este tenor ficcional que, pese a estar ya dados en la inmanencia del archivo, resultan resaltados por su labor selectiva: una relación de amistad solo interrumpida por la muerte (Guillén-Salinas), o de puro trato profesional (Salinas-GuillénSánchez Cuesta), o de admiración y respeto literarios acompañados de nuevo de una amistad que durante un tramo de su recorrido añadió el trato amoroso (Pardo Bazán-Galdós).

En todos los casos mencionados, el apasionante interés de lo biográfico y de lo no ficcional se proyecta sobre el espacio de lo ficcional y literario. En este territorio fronterizo, el editor es artífice del foco selectivo que permite tal presentación. El lector, afortunado destinatario, debería tener acceso a una aproximación al conjunto $-\mathrm{y}$ el editor debería estar en condiciones de ofrecerla-, toda vez que para la producción epistolar de escritores, casi siempre inédita, no contamos con referencias bibliográficas previas.

\section{DIALOGISMO, POLIFONÍA Y TEMPORALIDAD: DISPOSICIÓN DE LA MATERIA EPISTOLAR}

El intercambio de cartas en dirección de ida y vuelta nos indica una nueva categoría caracterizadora del género: el especial dialogismo de la carta (Demetrio, 1996; Salinas, 1967; Altman, 1982: 42-43, 88, 136; Fumaroli, 2013: 16; MacArthur, 1990: 75; Stanley, 2004: 213), si ceñimos nuestra atención al intercambio entre dos corresponsales; y una también peculiar polifonía (Neira, 2003) si nuestra perspectiva adopta la incorporación de varias o de todas las voces epistolares contenidas en un solo archivo. Este interés hacia el dialogismo epistolar, abordado desde múltiples enfoques de investigación, contrasta nuevamente con la casi total falta de atención desde una perspectiva ecdótica.

También en este ámbito encontramos al editor como autor. Si ante el archivo se encontraba con una tarea de selección, aquí el editor se enfrenta a una labor compositiva que, en obras preparadas por sus autores, cae en el ámbito de decisión de estos. En el caso de la edición de cartas, no solo se trata de dilucidar qué editar y qué no editar sino, una vez seleccionado el material, decidir el modo de ordenarlo, de disponerlo y presentarlo al lector. Esta decisión no es neutra, pues condicionará la focalización discursiva de las voces autoriales incorporadas a la edición, así como su ordenación, casi 
siempre realizada con un criterio de sucesión cronológica.

De nuevo hallamos algunos de los factores que intervienen en el proceso de edición: el carácter autónomo y a la vez dependiente de la carta - rasgo genérico-, su versatilidad y las múltiples facetas que conforman una unidad epistolar: su fecha, su destinatario, su asunto, su posible respuesta o respuestas. En todos ellos, de haberse dado una edición del autor, este habría decidido en una determinada dirección. Como en el caso de la selección, los editores también eligen y construyen la disposición y ordenación del material seleccionado. Las combinaciones posibles son numerosas y todas ellas aportan un grado de intervención en la construcción del sentido de la selección editada. Veamos algunos casos que pueden ilustrar el papel autorial de los editores en este ámbito.

Un ejemplo elocuente es el de las cartas de Gertrudis Gómez de Avellaneda a Ignacio de Cepeda, editadas por Lorenzo Cruz de Fuentes (1907). El editor, en su introducción, las presenta como relato de un apasionado enamoramiento de juventud que hacia 1840 se enfría y se transforma en amistad. Las cartas donadas por el receptor y la publicación a expensas de su viuda, María de Córdova y Govantes, tal como leemos en la portada de la propia edición, resultan orientadas a una construcción de la imagen de la escritora - mostrada como estereotipo de mujer romántica, apasionada, arrebatada y celosa - y del destinatario de sus cartas, Ignacio de Cepeda — presentado como personaje templado y juicioso-.

Tal como han señalado Pagés-Rangel (1997a y 1997b) y Delgado (2008), el tratamiento ecdótico practicado juega un papel de primer orden en esta presentación: la ausencia de fechas y rúbricas permite una ordenación libre del material, moldeado por el editor sin que tengamos constancia de su estricta cronología. Añadamos nosotros que solo contamos con la voz de Gómez de Avellaneda. La de su corresponsal permanece ausente durante todo el epistolario, salvo en una extensa y muy elegida carta que cierra la edición, en nota al pie a la última misiva de Gómez de Avellaneda, ocupando más de tres páginas y que podemos tomar como un evidente montaje compositivo. Tanto la ubicación de esta carta de Cepeda, cerrando el discurso epistolar de la escritora, como su contenido, que nos lo presenta en su plena madurez, sereno, dueño de su destino y en la cúspide de su carrera profesional, contribuyen a la construcción de las dos identidades de los corresponsales en manos del editor. Además, resulta significativa la ubicación de las cartas de Gómez de Avellaneda en el espacio del cuerpo 
del texto, que el lector podría identificar con lo creativo y pasional, con el espacio de la ficcionalidad literaria, y la ubicación de la carta de Cepeda, que se sitúa en el aparato crítico, espacio de la racionalidad, del juicio y del escrutinio.

Esta edición contrasta con la correspondencia de la misma autora, publicada en 1929 por Domingo Figarola-Caneda (Gómez de Avellaneda, 1929). Contiene cartas recibidas y cartas enviadas por Gertrudis Gómez de Avellaneda. Entre las recibidas, se incluyen cerca de cien cartas de cuarenta y seis remitentes, todos ellos figuras destacadas del mundo de las letras, de la política y de las artes (Nicasio Gallego, Donoso Cortés, Lista, García Tassara, Martínez de la Rosa, Pardo Bazán, Cristino Martos, Concepción Arenal, Hartzenbusch, Zorrilla...). Entre las cartas enviadas por la autora, hallamos similares características: diez y nueve destinatarios y varias redacciones de periódicos.

En la edición de Figarola-Caneda la presentación del material, su disposición, sigue un estricto orden alfabético, al margen de su datación cronológica, una disposición que configura y nos remite, más que a un relato cronológico, a un catálogo de personalidades con las que la autora trabó relación personal, literaria y epistolar.

La selección de remitentes y la composición ecdótica dan lugar a una obra completamente distinta en intención a la edición de Cruz de Fuentes. Tan autora es Gertrudis Gómez de Avellaneda en la edición de 1907 como en la de 1929. Es la selección de las unidades epistolares y su ordenación, a manos del editor, la que ofrece una presentación de la autora radicalmente distinta en cada caso. Se trata de un caso extremo, pero sin duda ilustrativo de los medios de creación que el editor activa cuando asume determinadas opciones y decisiones ecdóticas.

Más cercanas, y por motivos radicalmente distintos y aun opuestos al caso anterior, las ediciones de Carlos García sobre los intercambios epistolares mantenidos por Guillermo de Torre con diversos corresponsales (Cansinos Assens y Torre, 2004; Jiménez y Torre, 2006; Giménez Caballero y Torre, 2012; Salinas y Torre, 2018) son un ejemplo igualmente ilustrativo de las posibilidades de la composición en la ecdótica epistolar. Pues en este caso, tratándose siempre de ediciones bidireccionales, el editor procede al rellenado de los huecos epistolares con documentos coetáneos, cartas de terceros o textos periodísticos, seleccionados y dispuestos entre las cartas propiamente dichas, lo que contribuye a la reconstrucción del contexto 
elidido por la naturaleza discontinua de la correspondencia. El editor trabaja aquí como autor acabando el dibujo que las cartas ofrecen solo en su esbozo y completando el cuadro argumental de la narración que ofrecen las unidades epistolares. Un cuadro conocido y compartido en su totalidad por los corresponsales, de indudable valor para los lectores alejados de tal contexto.

Como vamos observando en cada una de las operaciones de la edición, uno de los objetivos de la tarea ecdótica debería ir en la dirección de explicitar la esfera de decisiones del editor y distinguirla del conjunto de posibilidades que el archivo epistolar de un autor potencialmente contiene. Pues en muchos casos asistimos a una labor de montaje similar al cinematográfico. El editor desecha y ensambla materiales y lo hace casi siempre con una orientación narrativa que aleja, en mayor o menor medida, el producto editado del original archivo de procedencia. Como expresa con claridad Andreu Jaume en su edición de las cartas de Jaime Gil de Biedma, el objetivo de la selección y disposición del material es "montar una secuencia autobiográfica" (2010: 10). Las dificultades de edición del archivo completo, su carácter de inerte depósito documental, contrastan con la dimensión narrativa, con la construcción de sentido en los procesos ecdóticos de selección y ordenación, algo permitido y aun propiciado por la maleabilidad de las unidades epistolares, por las teselas del mosaico.

Por este motivo, el apartado descriptivo del archivo que mencionábamos al comentar la selección debería formularse como representación de la red de relaciones epistolares de tal archivo, cualidad del mismo en estrecha relación con los rasgos de dialogismo y polifonía de la escritura epistolar.

Recordemos, aquí, el concepto de stemma de la crítica textual lachmanniana, como árbol genealógico de los testimonios de una obra encadenados en el transcurso del tiempo, capaz de llevarnos a la reconstrucción del original del autor a través de la collatio y la emmendatio (Blecua, 2001; Pérez Priego, 2011). Proponemos, en este sentido, la aplicación de tal concepto, con todos los ajustes pertinentes, para la descripción de la red de corresponsales de un determinado archivo, más útil cuanto más completa.

Se tratará de un stemma, más que jerárquico y diacrónico — como en el caso de la crítica lachmanniana—, relacional y sincrónico, con igual jerarquía en todos sus testimonios - la totalidad de cartas enviadas y 
recibidas-, que nos ayudará a completar la topografía epistolar de un autor y contribuirá a reconstruir, hasta donde sea posible, su archivo completo. Este archivo, ideal y figurado, pero ecdóticamente pertinente, ocuparía el lugar del original autógrafo en la crítica textual de la tradición manuscrita.

Cabe solo mencionar aquí las posibilidades que ofrecen las humanidades digitales para ensamblar tales stemmata hasta confeccionar un gran mapa de intercambio de correspondencias, sin duda útil para un mejor conocimiento de estas, así como para las decisiones ecdóticas de selección. La finalidad última sería la puesta en marcha de ediciones integrales, como práctica de edición, pero también como categoría teórica, propuesta por Neira (2003: 13-17).

\section{TÍTULOS, CREACIÓN AUTORIAL Y TERMINOLOGÍA DEL GÉNERO: EPISTOLARIOS, CORRESPONDENCIAS, CARTAS... Y MÁS}

Tras los procesos de selección y ordenación del material, los títulos de las ediciones ofrecen un nuevo espacio en que el editor decide por el autor.

En este ámbito encontramos dos grandes grupos de decisiones, con una enorme variedad y, también, cierta arbitrariedad entre las elecciones adoptadas. En un primer grupo hallamos títulos que incorporan, junto al nombre del autor o autores, los términos cartas, correspondencia o epistolario, acompañados casi siempre del marco temporal de las unidades epistolares editadas. Los protagonistas y el marco temporal del intercambio son referencias estables, pero la variedad abunda en la denominación del material de intercambio. Un repaso a las ediciones consultadas nos indica veintiséis ediciones tituladas como "Epistolario", otras veintiséis como "Cartas", y una docena como "Correspondencia". Recordemos a este propósito las modalidades de presentación y ordenación de las unidades epistolares: cartas de un autor a uno o varios destinatarios, de varios autores a un mismo destinatario, cartas cruzadas entre dos o más corresponsales, todas las cartas de un autor con sus respuestas disponibles... Con matices, comprobamos que tales formatos de presentación del material epistolar se corresponden, respectivamente, con los términos que señalamos en el presente parágrafo.

Con el objetivo de poner un poco de orden en la nomenclatura 
de los títulos, resultaría adecuado, ateniéndonos a lo descriptivo de tales términos, ajustar cada uno de ellos al tipo de edición realizada: destinar la denominación cartas para aquellas ediciones en las que selección y disposición se realizan con uno o varios emisores pero en una única dirección; correspondencia para ediciones en las que se produce una verdadera correspondencia, un intercambio bidireccional de unidades epistolares, sea de uno o de varios corresponsales; y epistolario, finalmente, que incorpora un sufijo latino con el significado de depósito, para una edición con intención de exhaustividad, para unas eventuales cartas completas, modalidad que, entre las tres mencionadas, se acercaría con mayor precisión al concepto ecdótico de archivo. Para hacernos una idea de la azarosa aplicación de estos términos en las ediciones consultadas, baste mencionar el hecho de que cerca de la mitad de las rotuladas como "epistolarios" son, en realidad, "correspondencias" cruzadas entre dos autores.

Un segundo grupo de títulos lo conforman aquellos en los que, más allá de la modalidad epistolar, el editor incorpora una fórmula de creación propia, un título del que es, literalmente, autor. En este segundo grupo hallamos, en un extremo de mínima apropiación autorial, los casos de los apenas perceptibles matices añadidos a los títulos descriptivos del género, como en las Cartas a Germaine (Guillén, 2010), en las que el nombre de la destinataria, primera esposa de Jorge Guillén, juega un papel emotivo que no se hubiese dado con la incorporación del apellido (Cahen), habitualmente incorporado en la mayoría de títulos descriptivos.

Un poco más allá, observamos también títulos que incorporan citas textuales, pero de gran carga expresiva, extraídas por el editor del propio material editado: "Miquiño mío". Cartas a Galdós (Pardo Bazán, 2013), Querido Salvador, querido Lorquito. Epistolario 1925-1936 (Dalí y García Lorca, 2013).

Finalmente hallamos títulos en los que el editor añade su propia contribución a la descripción del conjunto editado: Cartas de buena amistad. Epistolario de Emilia Pardo Bazán a Blanca de los Ríos (18931919) (Pardo Bazán, 2016), Gacetas y meridianos. Correspondencia 1925-1968 (Giménez Caballero y Torre, 2012).

En un extremo de apropiación observamos, una vez más, la edición de las cartas de Gertrudis Gómez de Avellaneda realizada por Cruz de Fuentes (1907). En la misma, incluso la disposición gráfica de 
los elementos de la portada da cuenta del alto nivel de intervención del editor: el nombre de este queda situado en el espacio destinado al autor en la distribución gráfica de los elementos de la portada y la autora, por su parte, recibe un tratamiento gráfico igualmente peculiar, pues se eliminan nombre y primer apellido, y se antepone un artículo determinado ("La Avellaneda") que casi la convierte en personaje, para quedar situada en el espacio gráfico reservado al título. Comparemos la edición de 1907 con la realizada en 1929 por Figarola-Caneda, tal como hicimos al analizar la selección y disposición de ambas ediciones, para observar cómo sus distintos enfoques se reflejan en las portadas respectivas.

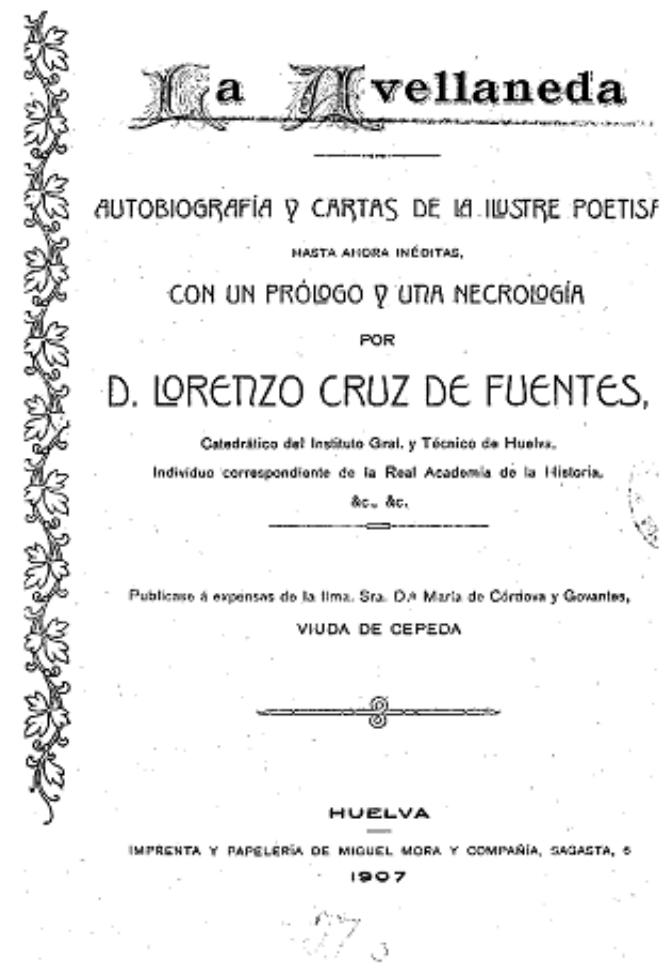

Figura 1. Cartas de Gertrudis Gómez de Avellaneda.

Edición de Lorenzo Cruz de Fuentes. 


\section{GERTRUDIS GOMEZ DE A VELLANEDA}

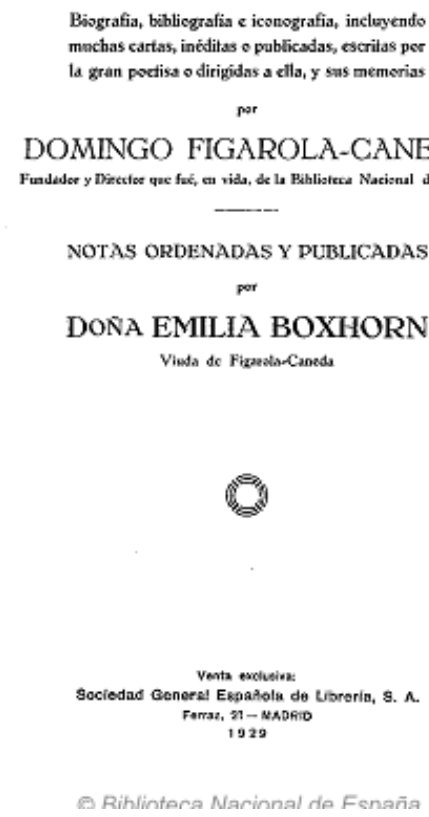

Figura 2. Cartas de Gertrudis Gómez de Avellaneda.

Edición de Domingo Figarola-Caneda.

Finalmente, para cerrar este apartado, conviene reparar también en la inclusión de capítulos con sus respectivos títulos, una vez más a cuenta del editor. Se trata de una práctica menos habitual (Alonso y Bataillon, 2013; Pardo Bazán, 2013) pero que nos recuerda su uso en los repertorios líricos de nuestro Siglo de Oro, en textos que sus autores tampoco prepararon para la edición en la mayoría de los casos (Blecua, 2001: 190-191). 


\section{LA CONSTITUTIO Y LA DISPOSITIO TEXTUS Y EL PROCESO DE TRANSCRIPCIÓN: EL PALIMPSESTO EPISTOLAR}

Llegado el momento de trasvasar los documentos originales al formato impreso, hallamos tres rasgos de género que condicionan la operación de la transcripción: en primer lugar, la provisionalidad o urgencia de la comunicación epistolar, a continuación, el carácter personal y privado de la misma, así como, en último lugar, la ausencia de intención de publicar tales textos por parte de los autores.

Además, como han señalado Stanley (2004: 209) y MacArthur (1990), la escritura epistolar ofrece un marcado carácter metonímico del autor. Tal rasgo, que describe la significativa inmediatez material, biográfica e histórica del texto respecto al momento de su escritura y a los hechos referidos, representa uno de los mayores atractivos que los testimonios epistolares ofrecen a investigadores y lectores (y hablamos de testimonio en su doble acepción, ecdótica e histórica).

Tales rasgos imprimen en los originales una serie de características que convierten a la carta privada tal vez en el caso ecdótico en el que mayor distancia se da entre el original manuscrito y el texto editado e impreso. Sin contar con la puesta en limpio de una versión definitiva por parte del autor y mucho menos con su intervención en la corrección de pruebas, la carta privada contiene una multitud de señales que el editor deberá procesar, forzosamente a veces, opcionalmente otras, para ofrecer al lector un texto legible en su formulación impresa.

Así, el editor de cartas se encuentra con tachones, abreviaturas, iniciales, siglas, disposición del texto en los márgenes o en los ángulos del soporte, manchas, membretes, tipos de papel, ortografía, acentuación y puntuación alejadas de la norma. No se trata únicamente de cerrar una escritura de carácter provisional, sino, en ocasiones, de trasladar a las posibilidades de la página impresa la enorme versatilidad y apertura gráfica del original, incompatible en ocasiones con aquella.

Ofrecemos solo un ejemplo. Observemos en la siguiente carta inédita de Elisabeth Mulder a Consuelo Berges, fechada el 4 de junio de 1951, un caso extremo de metonimia epistolar: un accidente físico del soporte, una quemadura en el papel, causado por la autora, tratado y anotado de su mano mediante una nota al pie: "Chispa saltada sobre el 
papel al encender un cigarrillo". Un juego entre soporte y texto, especular del asunto que estamos tratando en estas páginas — pues aquí la autora se comporta como editora - que el editor a su vez deberá trasladar a la edición impresa.

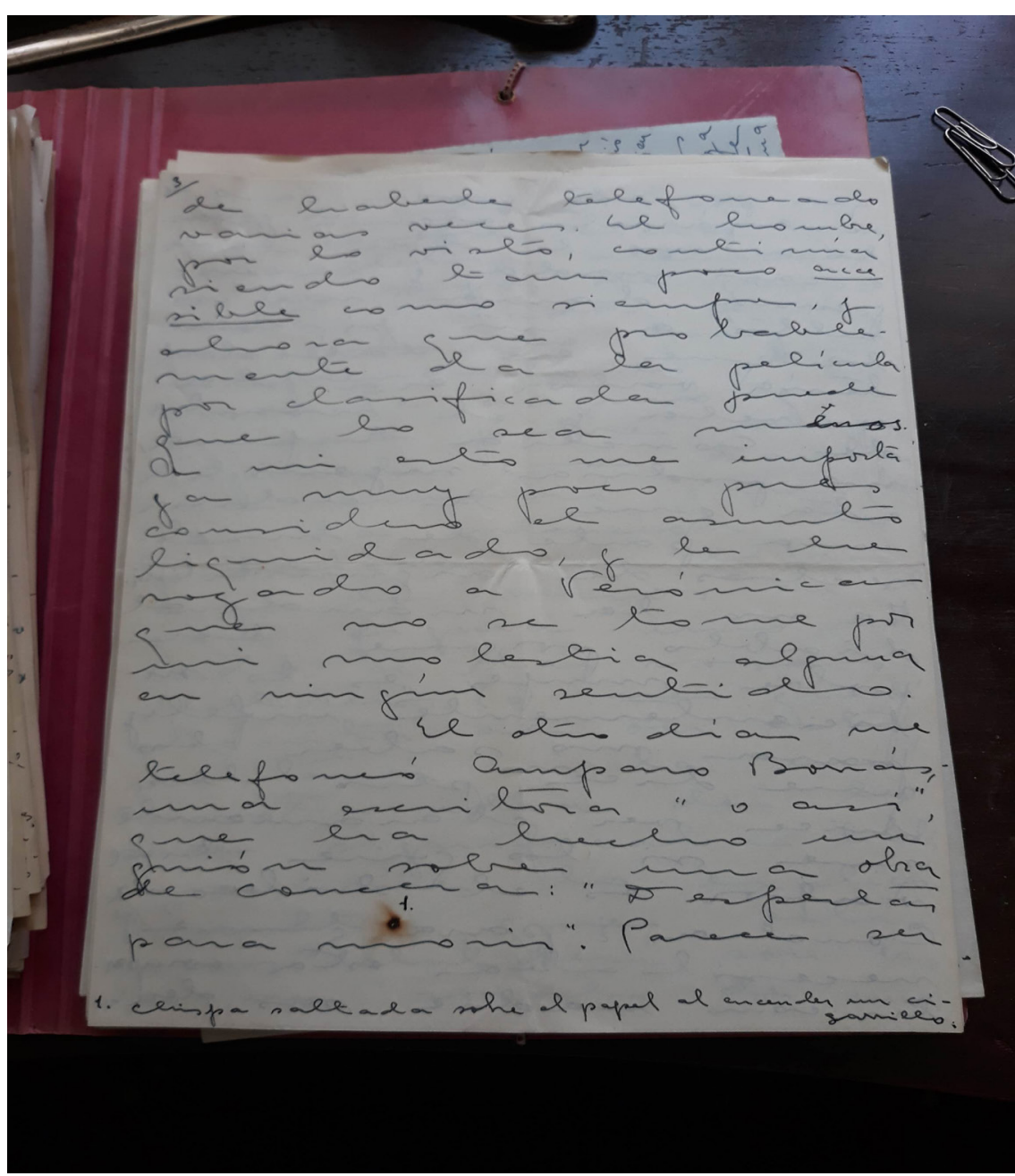

Figura 3. Carta autógrafa de Elisabeth Mulder a Consuelo Berges.

Thion (2017) ha dedicado un preciso y útil acercamiento a tales cuestiones. El tratamiento de estos elementos resulta fundamental para una edición rigurosa, si nos atenemos a la apropiación del editor del cierre 
que hubiera efectuado el autor. Observamos que una fase del proceso creativo, del proceso de escritura, queda en manos del primero: qué hacer con los tachones, añadidos y el resto de accidentes gráficos que hemos mencionado, con las incongruencias ortográficas o con la puntuación y la acentuación. Para valorar las implicaciones de tales intervenciones pensemos, por ejemplo, que estos últimos elementos, puntuación y acentuación, dan soporte al carácter fronterizo entre lo oral y lo escrito que las cartas privadas mantienen como pocos documentos, aunque (o precisamente porque) lo hacen con una enorme fragilidad. Tenemos aquí un rasgo del género, señalado por Claudio Guillén (2008: 112), que al igual que el resto tiene consecuencias ecdóticas. Una intervención editorial excesiva, tal vez con la prerrogativa de la estandarización, arruinará la frágil marca prosódica cuyo único testimonio material permanece, con sus incongruencias y vacilaciones, en la puntuación original.

Entre las ediciones examinadas, hay una variedad de opciones que van del más escrupuloso respeto a los originales (Alonso y Bataillon, 2013) a la corrección y adaptación de los mismos (Aleixandre, 2001, a cargo de Irma Emiliozzoli, aunque junto a esta edición podríamos citar la mayoría de las recientes).

En cualquiera de las opciones, debe considerarse la explicación, justificación y puesta en práctica de las decisiones adoptadas para, posteriormente, valorar su adecuación ecdótica. Pues el objetivo de una edición rigurosa, y su condición, debería consistir en ofrecer al lector información precisa de aquello que pertenece al original y aquello que modifica o interpreta el editor. No se trata, como decía Agustín Gómez de Amezúa en su edición de las cartas de Lope de Vega al duque de Sessa, de una simple reproducción, debido a "la violencia y repulsión que hubiera traído consigo la reproducción ciega y mecánica de las cartas de Lope. Aspiro con ello a presentar una edición crítica, no una fotocopia" (Gómez de Amezúa, 1989: LXXX). Pero precisamente por tal aspiración al carácter crítico de la edición, el editor debería dar cumplida cuenta de su intervención en el texto y evitar, en lo posible, una elaboración del mismo que lo convierta en autor, ahora en la fase final de terminación y pulido del texto epistolar.

En la mayoría de las ediciones recientes, como decimos, hallamos un grado de intervención medio, pues se nos informa de la actualización ortográfica y la uniformación de acentuación y puntuación. Importa también 
la distinción entre ediciones - la mayoría — que marcan tipográficamente la intervención del editor sobre el texto original, habitualmente mediante la señalización de la misma entre corchetes, de aquellas que no distinguen tal intervención y hacen por tanto imposible la identificación de ambos focos textuales, como en el caso, entre otras, de la edición de las cartas de Pedro Garfias (2017).

En el extremo de la intervención encontramos un nuevo ejemplo del siglo XIX señalado por René Andioc en su edición del Epistolario de Leandro Fernández de Moratín (1973). Se trata de la colección de cartas publicada por Hartzenbusch en 1867-1868, en los tomos II y III de las Obras póstumas del primero, en la que encontramos una reescritura del texto, con intervenciones que tienen que ver tanto con la ausencia de una práctica filológica rigurosa como con la censura moral y la transmisión adulterada de los originales. Como explica Andioc (1973) en su edición del epistolario de Moratín —esta sí, filológica y respetuosa con los originales-, nos encontramos en la de Hartzenbusch con un extenso catálogo de intervenciones del editor:

Pero, por otra parte, la primera edición del epistolario de D. Leandro ha dejado ya de responder a las normas actualmente exigidas en materia de publicación de documentos: la ortografía no es la de Moratín sino la oficial de finales del XIX; las notas aclaratorias son escasísimas; se trastorna la colocación de no pocas cartas sin fecha a consecuencia de un análisis demasiado somero; más aún, muchos pasajes tenidos por ofensivos a ciertos cuerpos o principios se han suprimido deliberadamente, quedando mutilada la personalidad del escritor; por fin el propio Inarco falsificó algunos textos, de manera que no todas las cartas merecen el mismo crédito (Andioc, 1973: 11-12).

Lo que a su vez debería llevarnos a reflexionar sobre las consecuencias que el inevitable paso del tiempo traerá sobre cualquier práctica ecdótica sujeta a las normas y hábitos del momento de la edición.

En el otro extremo, el de la conservación de los rasgos gráficos de los originales, podemos citar la edición de Dámaso Alonso y Marcel Bataillon (2013), a cargo de Estrella Ruiz-Gálvez Priego. En ella se detalla la señalización ecdótica de los accidentes gráficos del original, en su mayor parte conservados. Es decir, se da cuenta de la forma con que la editora representa tales accidentes en el texto editado y se nos ofrece además, 
en cierta medida, una aplicación de la crítica textual a los documentos epistolares.

Detengámonos en ello, pues tales herramientas de señalización textual pueden resultar productivas para la edición de textos epistolares.

No podemos olvidar que la carta, en su provisionalidad, conserva gráficamente y en un único soporte material un lapso de tiempo que deja a la vista los rastros de su redacción y corrección, casi siempre apresuradas. Las marcas de la crítica textual, debidamente argumentadas y aplicadas, nos permiten conservar y transmitir la frágil y huidiza textura temporal de la redacción epistolar, de un original con sobreescrituras, tachones, añadidos al margen y post scripta, cuando no con la aparición de dos o más autores. Así, en la citada edición de las cartas cruzadas entre Dámaso Alonso y Marcel Bataillon, su editora nos describe la señalización gráfica utilizada para los sobreescritos en interlínea, las tachaduras, la continuación de escritura sobre los márgenes del texto principal, las aposiciones laterales o los subrayados, por citar algunos casos. Fenómenos y accidentes gráficos que remiten, todos ellos, a un orden temporal de extensión breve pero conservado en los originales con igual transparencia que el pequeño insecto atrapado en un fragmento de ámbar.

Pocas obras son tan materialmente temporales como las cartas. Con la omisión de tales rasgos, el editor escribe de su propia mano sobre tan frágiles rastros del tiempo, plegándose a un horizonte de expectativas que también incumbe a la práctica ecdótica. Es así como, corrigiendo, sobreescribe y cierra un texto que de tal forma pierde una de sus más excepcionales virtudes. El editor, en este sentido, produce un palimpsesto que mantiene el original oculto bajo la capa uniformadora de la estandarización textual. Consideramos en este aspecto que es razonable un equilibrio entre legibilidad y conservación, con el sentido que Gómez de Amezúa otorgaba al carácter crítico de una edición. Es obligado admitir que un original puede requerir intervención, pero esta debe señalarse por el editor y mantener la excepcionalidad de la carta como documento y testimonio. 


\section{ALGUNAS CONCLUSIONES: POESÍA E HISTORIA EN LA EDICIÓN DE TEXTOS EPISTOLARES}

El recorrido realizado a través de las diferentes operaciones ecdóticas de la selección, la disposición y la transcripción en la edición de textos epistolares nos ha permitido identificar y describir la apropiación, en diferentes grados de intensidad, de algunas decisiones autoriales por parte del editor. Hemos observado igualmente que la motivación de tal fenómeno proviene de los rasgos del género epistolar, en su específica concreción de la carta privada, y de modo especial de la ausencia de preparación de tales textos para su publicación por parte de los autores.

Hemos dejado sin examen dos operaciones de relevancia en la edición de textos epistolares, la anotación y la confección de índices para la recuperación de la información. La razón es que ambas quedan marcadas gráficamente y con ello resultan diferenciadas del texto autorial. Pero merecerían atención como elementos de co-autoría.

Este recorrido nos puede llevar a continuar el camino aquí iniciado en varias direcciones, compatibles y coherentes entre sí.

En primer lugar, sería de utilidad contar con un panorama histórico de las prácticas ecdóticas en la edición de textos epistolares, tanto para conocer las diferentes soluciones técnicas adoptadas como para disponer de una lectura evolutiva de las estrategias de apropiación autorial por parte de los editores: qué colecciones y archivos han despertado interés en cada momento, qué criterios de selección y transcripción se han seguido, así como la intensidad y cualidad de las apropiaciones. Su descripción permitiría trazar una historia de la recepción de los textos epistolares, contribuiría a enriquecer la historia literaria y cultural y a profundizar en los elementos ideológicos que conforman una tarea aparentemente técnica como la edición de textos.

El estudio del comportamiento del editor como autor permitiría, en segundo lugar, contar con orientaciones teóricas para la aplicación práctica de la tarea ecdótica orientada a la carta privada. El conocimiento y la conciencia de las apropiaciones autoriales proporcionarían criterios de edición sustentados en la perspectiva filológica de las decisiones adoptadas. Y aquí la tarea fundamental es fijar unos textos que, en su fragilidad y su inmediatez, ofrecen una materialidad específica frente a otra tipología de textos y documentos, y ofrecerlos al lector dando cuenta de 
las intervenciones, cuando las haya, operadas en ellos desde la cuidadosa separación y justificación de las marcas del editor sobre el texto del autor. Solo así es posible, a nuestro juicio, conservar la específica naturaleza de los documentos epistolares.

Con estas dos líneas de trabajo, examen histórico y aplicaciones prácticas, la ecdótica epistolar se acercaría a las fronteras de la hermenéutica, dentro de la que podría situarse como una disciplina no secundaria. Pues como podemos leer en Verdad y método,

En realidad no es la historia la que nos pertenece, sino que somos nosotros los que pertenecemos a ella [...] La lente de la subjetividad es un espejo deformante. La autorreflexión del individuo no es más que una chispa en la corriente cerrada de la vida histórica. Por eso los prejuicios de un individuo son, mucho más que sus juicios, la realidad histórica de su ser (Gadamer, 1977: 344).

Junto a la consideración histórica y práctica que acabamos de señalar, la figura del editor como autor nos permite apuntar, en tercer y último lugar, una reflexión vinculada a la teoría literaria. Aristóteles, en su Poética, al tratar la diferente naturaleza de los géneros, distingue entre poesía e historia, distinción que ha provocado una larga tradición de comentarios. En un deslinde inaugural entre géneros ficcionales y no ficcionales, Aristóteles afirma que la poesía es más filosófica que la historia (Poética, IX, 1451b) ${ }^{2}$ por cuanto la segunda narra lo particular, lo que de hecho sucedió, y la primera lo universal, lo que podría haber sucedido, matizando, no obstante, que:

[...] aún cuando el poeta, accidentalmente, crea un tema a partir de hechos históricos, no por ello es menos poeta, pues nada se opone a que los hechos ocurridos realmente sean, por su naturaleza, necesarios o posibles, y es en virtud de ello por lo que él es su creador.

Más adelante (Poética, XXIII, 1459a-b), tratando de la unidad de acción de la epopeya, nos dice que:

\section{[...] los argumentos deben estar construidos dramáticamente, como}

2 Se cita por la edición y traducción de la Poética a cargo de José Alsina en Editorial Bosch (Aristóteles, 1977). 
en las tragedias, y en torno a una acción entera, con principio, medio $y$ fin, de modo que sea un todo, como un ser vivo [...] Y conviene que las composiciones no se parezcan a las historias habituales en las que necesariamente se expone, no una sola acción, sino un solo periodo de tiempo, es decir, lo que en tal tiempo sucedió a una o más personas, aunque entre estos acontecimientos exista solo una relación fortuita.

Pues bien, las diferentes prácticas adoptadas en la edición de textos epistolares se pliegan como ninguna otra modalidad de edición a esta distinción, a poco que reparemos en la naturaleza documental del archivo, por una parte, en el que las cartas constituyen elementos situados en contigüidad temporal, y las prácticas de los editores que seleccionando, disponiendo y transcribiendo tales documentos tienden a situarlos en una disposición causal. A la vista de las categorías de Aristóteles, las prácticas de edición epistolar representan un movimiento permanente y al parecer ineludible hacia la interpretación y hacia el sentido, hacia la poesía aristotélica que, para nosotros, habría que traducir como literatura.

Como expresa José Teruel en su edición de la correspondencia entre Juan Benet y Carmen Martín Gaite (2011: 9):

\begin{abstract}
[...] si concebimos este epistolario como un relato, la primera peculiaridad desde el punto de vista de la sucesión temporal y del propio discurso es su carácter discontinuo, interrumpido y elíptico. (En el fondo, todo epistolario como tratamiento temporal y fechado de la experiencia humana hace caso omiso de la imagen del tiempo concebida como un continuum y se concentra en la intensidad de determinados focos e intereses, cuya luz relega otros territorios al silencio y al olvido).
\end{abstract}

Una reflexión que ilustra certeramente esta peculiaridad de la ecdótica epistolar.

Terminamos con una carta. La de Jorge Guillén a Pedro Salinas, escrita el 28 de febrero de 1942, en la que encontramos estas palabras suscitadas por el suicidio de Stefan Zweig:

Pienso en el caso opuesto: en ese desventurado de Zweig. ;Horrible historia! Para llegar a ese desenlace, el sufrimiento debió ser tremendo. Pero lo que despierta en mí más piedad —al mismo tiempo que admiración-es que una vida humana se consuma integramente dentro de la Historia. Sublime, sí. ¿Y no había más? Pienso en lo que don Miguel llamaba la intrahistoria: 
esa cotidianidad sin fecha-el sol, la manzana, el hijo, la mujer, el trabajo de cada día, esta carta al amigo, esta ventana: exactamente, lo que no es Historia. Actualidad y podría ser Poesía, Poesía no-histórica. Esto no es la doctrina de Cántico: así es como viven y van saliendo adelante las miles de gentes, no deshechas del todo _-iaun!-por la Historia miserable que tan pequeño margen disponible deja en estos miserables días (Guillén y Salinas, 1992: 276).

A partir de Hegel la Historia, con mayúscula, con la que Jorge Guillén confrontaba en 1942, se había convertido en Poesía (en relato, decimos ahora). Aunque se le siguiera llamando historia. La crónica, los anales, la relación de los acontecimientos "unos detrás de otros", y junto a ellos la cotidianeidad, pasó a ser el relato de los mismos acontecimientos "unos a consecuencia de otros" (Pardo, 2010: 230-254, para una lectura contemporánea de tal distinción).

Parece inevitable ver en las cartas privadas un argumento, una sucesión de los hechos en el sentido poético de la historia, una causalidad. Este rasgo, creemos, se muestra como una constante en la ecdótica epistolar, en un movimiento que formaliza el archivo inerte - cargado como pocos materiales textuales con la nota de lo documental privado, como historia personal no procesada, como intrahistoria - y lo presenta como producto con un sentido, con una lección literaria, a través del troquel de las operaciones de la edición. En cualquier caso, una honesta aspiración de la edición filológica de cartas sería acercase lo más posible a la historia contada por las propias cartas y procurar que la inevitable huella del momento circunstancial de la edición se hiciera patente y explícita.

\section{REFERENCIAS BIBLIOGRÁFICAS}

ALEIXANDRE, V. (2001). Correspondencia a la Generación del 27 (1928-1984), Irma Emiliozzoli (ed.). Madrid: Castalia.

ALONSO, D. y BATAILLON, M. (2013). Dámaso Alonso-Marcel Bataillon: un epistolario en dos tiempos. 1926-1935: En torno al Enquiridion; 1949-1968: En torno al Hispanismo, Estrella Ruiz-Gálvez (ed.). Madrid: Fundación Universitaria Española.

AltMAN, J. G. (1982). Epistolarity. Approaches to a form. Columbus: Ohio State University Press. 
ALTOLAGUIRRE, M. (2005). Epistolario 1925-1959, James Valender (ed.). Madrid: Publicaciones de la Residencia de Estudiantes.

ANDIOC, R. (1973). "Introducción". En Epistolario, L. Fernández de Moratín, 11-34. Madrid: Castalia.

ARISTÓTELES (1977). Poética, ed. y trad. José Alsina. Barcelona: Editorial Bosch.

BLECUA, A. (2001). Manual de crítica textual. Madrid: Castalia.

BOU, E (2006). "La edición de epistolarios: autor y lector". En Seminario de archivos personales (Madrid, 26 a 28 de mayo de 2004), Julián Martín Abad (coord.), 251-258. Madrid: Biblioteca Nacional.

CABALLÉ, A. (2006). "El bolso de Ana Karenina. La necesidad de inventariar los textos autobiográficos". En Seminario de archivos personales (Madrid, 26 a 28 de mayo de 2004), J. Martín Abad (coord.), 195-211. Madrid: Biblioteca Nacional.

CANSINOS ASSENS, R. y TORRE, G. de (2004). Correspondencia 1916-1955, Carlos García (ed.). Madrid-Frankfurt am Main: Iberoamericana-Vervuert.

CHACEL, R. (1992). Cartas a Rosa Chacel, Ana Rodríguez-Fischer (ed.). Barcelona: Versal.

DALÍ, S. y GARCÍA LORCA, F. (2013). Querido Salvador, querido Lorquito. Epistolario 1925-1936, V. Fernández y R. Santos Torroella (eds.). Barcelona: Elba.

DELGADO, L. E. (2008). "Gertrudis Gómez de Avellaneda: escritura, feminidad y reconocimiento". En La mujer de letras o la letraherida. Discursos y representaciones sobre la mujer escritora en el siglo $X I X$, P. Fernández y M. L. Ortega (eds.), 201-220. Madrid: Consejo Superior de Investigaciones Científicas.

DEMETRIO (1996). Sobre el estilo. Madrid: Gredos.

DÍAZ DE CASTRO, F. J. (1998). "La autobiografía del 27: los epistolarios". Monteagudo [3. "época] 3, 13-36.

DIEGO, G. (2001). Gerardo Diego y el III centenario de Góngora (correspondencia inédita), G. Morelli (ed.). Valencia: Pre-Textos.

(2003). Epistolario santanderino, J. Neira (ed.). Santander: Ayuntamiento de Santander.

DIEGO, G.; GUILLÉN, J. y SALINAS, P. (1996). Correspondencia (1920-1983), J. L. Bernal (ed.). Valencia: Pre-Textos.

DÍEZ DE REVENGA, F. J. (coord.) (1998). Monteagudo [3. época] 3 
[Monográfico sobre Epistolarios y Literatura del siglo XX].

DOLFI, L. y BERNAL, J. L. (eds.) (2014). Cuadernos AISPI. Revista semestral de la Associazione Ispanisti Italiani 3 [Monográfico sobre Epistolarios del siglo XX].

FERNÁNDEZ DE MORATÍN, L. (1973). Epistolario, R. Andioc (ed.), Madrid: Castalia.

FERNÁNDEZ, P. y ORTEGA, M. L., (eds.) (2008). La mujer de letras o la letraherida. Discursos y representaciones sobre la mujer escritora en el siglo XIX. Madrid: Consejo Superior de Investigaciones Científicas.

FUMAROLI, M. (2013). La república de las letras. Barcelona: Acantilado.

GADAMER, H. G. (1977). Verdad y método. Salamanca: Ediciones Sígueme.

GARCÍA LORCA, F. (1997). Epistolario completo, A. A. Anderson y Ch. Maurer (eds). Madrid: Cátedra.

GARFIAS, P. (2017). Epistolario y otros textos, J. M. Barrera (ed.). Osuna: Ayuntamiento de Osuna.

GARRIGA, A. y TERUEL, J. (2018) "Introducción: de la teoría a la circunscripción histórica". En Historia e intimidad. Epistolarios y autobiografía en la cultura española del medio siglo, J. Teruel (ed.), 9-31. Madrid-Frankfurt am Main: Iberoamericana-Vervuert.

GIMÉNEZ CABALLERO, E. y TORRE, G. de (2012). Gacetas y meridianos. Correspondencia 1925-1968, Carlos García y María Paz Sanz Álvarez (eds.). Madrid-Frankfurt am Main: IberoeamericanaVervuert.

GÓMEZ DE AMEZÚA, A. (1989). "Introducción al epistolario de Lope de Vega y Carpio". En Epistolario, L. de Vega Carpio, vol. 3, I-XCVIII. Madrid: Real Academia Española.

GÓMEZ DE AVELLANEDA, G. (1907). Autobiografía y cartas de la ilustre poetisa / hasta ahora inéditas, L. Cruz de Fuentes (ed.). Huelva: Imprenta y Papelería de Miguel Mora (1929). Biografía, bibliografía e iconografía, incluyendo muchas cartas, inéditas o publicadas, escritas por la gran poetisa o dirigidas a ella, y sus memorias, D. Figarola-Caneda y E. Boxhorn (eds.). Madrid: Sociedad General de Librería.

GONZÁLEZ GARCÍA, J. M. (2014). "El proyecto Epistola: edición digi- 
tal de los epistolarios de la Edad de Plata". Humanidades Digitales: desafios, logros y perspectivas de futuro. Janus, Anexo 1, 197-208. GUILLÉN, C. (1998). "La escritura feliz: literatura y epistolaridad". En Múltiples moradas, C. Guillén, 177-243. Barcelona: Tusquets. (2008). "Para el estudio de la carta en el Renacimiento". En La poesía del Siglo de Oro. Géneros y modelos, B. López Bueno (dir.), 101-127. Sevilla: Universidad de Sevilla.

GUILLÉN, J. (2010). Cartas a Germaine (1919-1935), M. Ramírez (ed.). Madrid: Galaxia Gutenberg-Círculo de Lectores.

GUILLÉN, J. y SALINAS, P. (2016). Epistolario. Correspondencia con León Sánchez Cuesta 1925-1974, J. M. González (ed.). Madrid: Publicaciones de la Residencia de Estudiantes.

JAUME, A. (2010). "Narciso en Calibán: Jaime Gil de Biedma en sus cartas". Introducción a El argumento de la obra: Correspondencia (1951-1989), Jaime Gil de Biedma, 9-38. Barcelona: Lumen.

JIMÉNEZ, J. R. y TORRE, G. de (2006). Correspondencia 1920-1956, C. García (ed.). Madrid-Frankfurt am Main: Iberoeamericana-Vervuert.

LLUCH-PRATS, J. (2011). "Entre las heridas de un texto y la protección de su autor: el acceso al patrimonio literario". En El escritor en la sociedad de la comunicación, P. Fernández y J. Lluch-Prats (eds.), 129-157. Arbor. Anejo 6. Madrid: CSIC.

MACARTHUR, E. J. (1990). Extravagant narratives. Closure and dynamics in the epistolary form. Princeton, New Jersey: Princeton Universitiy Press.

MARTOS, M. y NEIRA, J. (eds.) (2018). Identidad autorial femenina y comunicación epistolar. Madrid: UNED.

MORELLI, G. (ed.) (2001). Epistolarios del 27: el estado de la cuestión. Actas del Congreso Internacional, Bérgamo, 12-13 de mayo de 2000. Viareggio-Lucca: Mauro Baroni Editore.

NEIRA, J. (2000). "Hacia un modelo de reconstrucción global. Epistolarios de Hinojosa y Gerardo Diego". En Epistolarios del 27: el estado de la cuestión. Actas del Congreso Internacional, Bérgamo, 1213 de mayo de 2000, G. Morelli (ed.), 149-164. Viareggio-Lucca: Mauro Baroni Editore.

(2002). La edición de textos: poesía española contemporánea. Madrid: UNED. 
(2003). "Introducción”. En Epistolario santanderino, G. Diego, 1151. Santander: Ayuntamiento de Santander.

(2018). "La correspondencia de Caballero Bonald: propuesta metodológica para una historia epistolar del medio siglo". En Historia e intimidad. Epistolarios y autobiografía en la cultura española del medio siglo, J. Teruel (ed.), 115-131. Madrid-Frankfurt am Main: Iberoamericana-Vervuer.

PAGÉS-RANGEL, R. (1997a). De dominio público: itinerarios de la carta privada. Amsterdam-Atlanta, GA: Editions Rodopi B.V.

(1997b). "Para una sociología del escándalo: la edición y publicación de las cartas privadas de Gertrudis Gómez de Avellaneda". Revista Hispánica Moderna 50.1, 22-36.

PARDO, J. L. (2010). Nunca fue tan hermosa la basura. Barcelona: Galaxia Gutenberg-Círculo de Lectores.

PARDO BAZÁN, E. (2013). “Miquiño mío”. Cartas a Galdós, I. Parreño y J. Manuel Hernández (eds.). Madrid: Turner.

(2016). Cartas de buena amistad. Epistolario de Emilia Pardo Bazán a Blanca de los Ríos (1893-1919), A. M. Freire López y D. Thion Soriano-Mollá (eds.). Madrid-Frankfurt am Main: Iberoeamericana-Vervuert.

PÉREZ PRIEGO, M.A. (2011). La edición de textos. Madrid: Síntesis.

PULIDO, G. (2001). "Escritura epistolar en la actual encrucijada genérica". Signa. Revista de la Asociación Española de Semiótica 10, 435-448. (También existe edición digitalizada sin paginar de la Biblioteca Virtual Miguel de Cervantes: http://www.cervantesvirtual.com/portales/signa/obra-visor/signa-revista-de-la-asociacion-espanola-de-semiotica-4/html/02598914-82b2-11df-acc7-002185ce6064_39.html\#I_78_[06/03/2020]).

SALINAS, P. (1967). "Defensa de la carta misiva y de la correspondencia epistolar". En El defensor, P. Salinas, 17-115. Madrid: Alianza Editorial.

(1996). Cartas de viaje [1912-1951], E. Bou (ed.). Valencia: Pre-Textos.

SALINAS, P. y GUILLÉN, J. (1992). Correspondencia (1923-1951), A. Soria Olmedo (ed.). Barcelona: Tusquets Editores.

SALINAS, P. y TORRE, G. de (2018). Correspondencia (1927-1950), C. García y J. M. González (eds.). Madrid-Frankfurt am Main: 
Iberoamericana-Vervuert.

STANLEY, L. (2004). "The Epistolarium: On Theorizing Letters and Correspondences". Auto/Biography 12, 201-235.

TERUEL, J. (2011). "Juan Benet y Carmen Martín Gaite: historia de una correspondencia". Introducción a Correspondencia, C. Martín Gaite y J. Benet, 7-27. Barcelona: Galaxia Gutenberg-Círculo de Lectores.

(ed.) (2018). Historia e intimidad. Epistolarios y autobiografía en la cultura española del medio siglo. Madrid-Frankfurt am Main: Iberoamericana-Vervuert.

THION SORIANO-MOLLA, D. (2017). "Estudios epistolares: edición y metodología a partir de la correspondencia de Emilia Pardo Bazán". AIEMH. Revista de la Asociación Internacional para el Estudio de Manuscritos Hispánicos 3, 1-28.

TORRAS, M. (2001). Tomando cartas en el asunto. Las amistades peligrosas de las mujeres con el género epistolar. Zaragoza: Prensas Universitarias de Zaragoza.

Recibido el 15 de enero de 2020.

Aceptado el 13 de abril de 2020. 